\title{
Panel 2.18: Logistics, Information Technology (IT), and Telecommunications in Crisis Management
}

\author{
Dr. Terrence De Silva (Chair); ${ }^{1}$ Ms. Jyotsna Chikersal (Rapporteur); ${ }^{2}$ \\ Mr. Nigel Snoad (Panelist 1); ${ }^{3}$ Mr. Brent Woodworth (Panelist 2); ${ }^{4}$ \\ Dr. Cherif Ghaly (Panelist 3); ${ }^{5}$ Mr. Martin Catterall (Discussant) ${ }^{6}$
}

1. Deputy Director-General, Medical Services Ministry of Healthcare, Nutrition and Uva Wellassa

Development, Government of Sri Lanka

2. Informatics Systems Management Officer, World Health

Organization/South East Asia Region

3. Chief Information Office, United Nations Joint Logistics Centre, Rome, Italy

4. Worldwide Segment Manager, IBM Crisis Response Team, IBM Global Services

5. Chief, Information Technology Section, United Nations Office for the Coordination of Humanitarian Affairs (OCHA), Geneva, Switzerland

6. Director of Information Technology and Telecommunications, World Health Organization Headquarters

Keywords: coordination; crisis; effectiveness; information sharing; information technology (IT); logistics; management; preparedness; recovery; responders; response; telecommunication; tsunami

\section{Abbreviations:}

ICT $=$ information and communication technology

IT = information technology

UNJLC $=$ United Nations Joint Logistics Center

WGET = Working Group on Emergency

Telecommunications

WHO $=$ World Health Organization

Web publication: 17 November 2005

\begin{abstract}
This is a summary of the presentations and discussion of Panel 2.18, Logistics, Information Technology, and Telecommunications in Crisis Management of the Conference, Health Aspects of the Tsunami Disaster in Asia, convened by the World Health Organization (WHO) in Phuket, Thailand, 04-06 May 2005. The topics discussed included issues related to logistics, information technology (IT), and crisis communication pertaining to the responses to the damage created by the Tsunami. It is presented in the following major sections: (1) issues; (2) lessons learned; (3) what was done well; (4) what could have been done better; and (5) conclusions and recommendations. Each major section is presented in four sub-sections: (1) needs assessments; (2) coordination; (3) filling the gaps; and (4) capacity building.
\end{abstract}

De Silva T, Chikersal J, Snoad N, Woodworth B, Ghaly C, Catterall M: Logistics, information technology and telecommunications in crisis management.

Prehosp Disast Med 2005;20(6):464-467.

\section{Introduction}

Responders need accurate and timely information in order to distribute critical supplies, equipment, and resources effectively. Without appropriate information, the efforts often are inadequate, misdirected, or excessive. As a key enabler, information technology (IT) and telecommunications capability demand high priority within disaster management support. Cooperative, strategic, logistics planning is a critical component for the timely, adequate, and appropriate response to any disaster.

\section{Issues}

\section{Needs Assessment}

Disasters cause loss and damage to the local telecommunications infrastructures for both data and voice. A lack of or redundant telecommunication capacity causes delays in relief operations, and thus, requires prompt intervention from external sources.

Information technology plays a crucial role in supporting the assessments of disaster situations. Further operational platforms include systems to support tracking of human, financial, and logistical resources. The development of electronic templates, information systems with mobile computing facilities, and hand-held computing devices (PDAs) to collect and manage information could improve the efficiency further.

Consolidating and sharing the results of various assessments at the local and global levels would avoid duplication of work. More information flow among various groups is necessary to identify opportunities for consolidation.

Without proper supply chain management, supplies were sent without adequate needs assessment thereby resulting in wastage, unnecessary logistics congestions, and delays in filling the actual gaps.

\section{Coordination}

Inadequate coordination results in a duplication of efforts and a lack of overall, coordinated responses to high priority requirements. Better coordination 
would help in maximizing the use of existing infrastructure. To the extent possible, there should be a coordinated approach to communications infrastructure to avoid appearances of an exaggerated UN telecommunications presence, and to provide better alignment with the country capability.

\section{Filling gaps in provision of available services}

Most humanitarian relief agencies faced serious problems to establish effective communications (e.g., import, install, and operate (license) satellite communications). Governmental issues have hindered the effective use of such equipment. Similar challenges were faced in establishing high frequency/very high frequency (HF/VHF) communication networks.

Computerized information systems for tracking resources had to be developed during the event in order to provide "real-time" decision support information, comprehensive reporting and links to organizational systems, including legacy systems.

The major barriers in delivering timely and effective logistics support were the massive scope and the sudden onset of the disaster. The scale of the response caused congestion and confusion, and sometimes competition for logistics resources between agencies, which overwhelmed the capacity of suppliers and local transport hubs. Damage to the local infrastructure caused the "absorption capacity" to be reached while supplies still were arriving.

\section{Capacity building}

Better preparedness is imperative. Timely investments in flexible, scalable, and secure technology solutions for preparedness and damage mitigation are keys to an effective response. The national disaster plans should strengthen preparedness by building fault tolerant and redundant information and communication technology (ICT) capacities, related standard operating procedures, and competencies with personnel to manage in the event of a disaster.

\section{What Were the Lessons Learned?}

Timely and adequate IT and telecommunication resources are critical for disaster mitigation and relief efforts. Information technology and telecommunication systems should be a strategic element in the development of comprehensive preparedness plans (including early warning systems and alert mechanisms). Inventory of essential IT and telecommunications equipment should be maintained. Information and communication technology applications, deployment strategies, and operational procedures should be developed as part of preparedness planning.

Relief organizations should establish well-equipped standby operations rooms with adequate ICT to facilitate information flow within all levels of the organization and the national disaster management programs.

An important lesson learned from the private sector response to the Tsunami is that agreements already should be in place before a disaster strikes in order to allow for quick deployment and ensure inter-operability and integration with existing networks and services. It is not practical to begin reviewing agreements with new contractors and to train technical staff and users in the field to use new technologies during an emergency.

Information technology managers should be involved from Day 1 of the disaster response phase. Experienced IT staff should be placed in the field immediately, preferably mobilized from within the relief organization for the entire response phase (with backfilling arrangements in cooperation with the public and private sector). Information systems and information dissemination tools should be implemented rapidly with a potential to work in both connected and unconnected environments.

In most major disasters, telecommunication infrastructures have been damaged or destroyed. Rapid deployment of telecommunication equipment to re-establish communication links for incident management and resource deployment should be the highest priority during the response phase. Relief operations must have the capacity to communicate within and outside using external communication channels beside local ones.

During the recovery phase, destroyed infrastructure should be rebuilt in a sustainable manner. E-health (telemedicine and e-learning, for instance) could contribute to building capacity for future disaster responses.

Poor communications prevented the effective dissemination of valuable logistics information. Systematic supply chain analysis should be undertaken as an immediate remedy to poor communication. Currently, several supply chain processes still are largely manual-driven.

Competing supply chains caused a "bullwhip" effect in procurement, and led to significant congestion in the distribution network. More effective pre-disaster collaboration and agreements should be established to avoid similar situations.

In the early days of the response, there was insufficient transport capacity to meet needs, especially from strategic staging points to the affected area, and also for distribution.

National disaster plans that incorporate mechanisms for managing the logistics aspect (both at the central and peripheral level) of the response including customs, warehousing, and distribution plans should be developed.

Shortage of trained and experienced logistics staff led to significant internal reassignment. Ineffective processes and time to develop skills in local staff was a major barrier. The emphasis should be on the deployment of logisticians in the field as first responders, and local capacity for logisticians should be strengthened, along with the development of operational procedures and coordination mechanisms with national NGOs.

\section{What Was Done Well?}

\section{Needs assessments}

Information technology played a significant role in supporting the assessment of the disaster situation. Systems and processes were developed rapidly to support this role. Unprecedented levels of private sector responses added to the response immensely.

In Thailand, the adaptation of the "General Health Questionnaire-12" for identifying the levels of psychosocial distress in the community generated successful results. 
Geographical information systems (GIS) support in Sri Lanka, Indonesia, India, and the Maldives addressed temporary camps, displaced persons, number of deaths, injuries, and impacted primary healthcare centers and hospitals.

Projects are being initiated across Aceh Province and also in affected provinces in Sri Lanka to leverage ICT in areas such as strengthening the health information systems. Associated infrastructure shall build capacities to respond to future disasters with a potential to contribute to systemic post-disaster improvement of health systems often to a level exceeding pre-Tsunami conditions.

Many UN agencies contributed from an ICT perspective in the initial response phase as well as recovery phase. For example, in Indonesia, the World Food Program (WFP) Radio Room operates on a 24/7 basis monitoring $\mathrm{HF}$ and VHF networks equipped with VSAT, SAT phones, fax, PSTN lines (two wire telephone lines) and Global System for Mobile Communications (GSM).

In logistics support, agencies with an existing footprint responded quickly and offered assistance to "new agencies", i.e., the International Organization for Migration (IOM) in Aceh. Ninety-four percent of agencies conducted assessments with multi-disciplinary participation. Individual agencies worked well in assessing their own needs. Information sharing worked well in situations when the United Nations Joint Logistics Center (UNJLC) was present.

\section{Coordination}

Where possible, the UNJLC deployed logisticians and established coordination centers. The Working Group on Emergency Telecommunications (WGET) worked well in: (1) coordination and inter-operability of ICT networks; and (2) mobilization of surge capacity. The WGET is an open forum of UN agencies, NGOs, the Red Cross, the private sector, and academia.

Excellent cooperation among various UN agencies has been reported. The WHO installed a "common service ready" VSAT in Meulaboh, which could be shared with other agencies. Also, UNICEF agreed to coordinate the sharing and maintenance, including the installation and operation of any inter-agency wireless connections. Additionally, the United Nations High Commissioner for Refugees (UNHCR) has established the UN common calling frequencies.

Telecommunications companies from both the supply and operational side of the industry and from around the world, have come together to provide, install, and deliver a working telecommunications cable between Banda Aceh and Medan in Sumatra, Indonesia, enabling onward connectivity to Singapore, where much of the disaster recovery is being coordinated.

\section{Filling gaps in provision of available services}

In Sri Lanka, disease surveillance was strengthened using health-mapping activities. Telecommunication infrastructure for high-speed data transmission with voice and video connectivity both within and outside the country has been implemented in the countries.
Information and communication technology infrastructure deployment strategies were developed, and ICT infrastructures were established in the WHO field offices. Telecommunication plans developed for the WHO field staff supporting the health sector-WHO country offices in Sri Lanka and Indonesia had extended VSAT connectivity. VSAT connectivity was established at WHO field offices at Banda Aceh and Meulaboh and the offices were connected to three levels of the organization through the WHO's Global Private Network (GPN). Internet connectivity also was extended to Provincial and District health offices at Banda Aceh and Meulaboh through various means by the WHO.

Information flow for resource tracking was improved using Web-based systems. Partners such as Telecom sans Frontier (TSF) have been engaged in putting their expertise in telecommunications and experience at the service of long-term, solidarity projects.

\section{What could have been done better? \\ Needs Assessments}

More human resources are required with in-country, fieldrelated, ICT experience and complementary public health skills to assess the requirements and provide informed input for capacity-building initiatives.

There is a need for structured, shared, and well-maintained ICT systems (including global information system (GIS) spatial data) that are pre-configured to respond to needs assessments and information coordination between stakeholders. Such activities should be coordinated by a distinct entity tasked to fulfill this function.

In the area of logistics, rapid response needs are required to be aligned with the ability of agencies to coordinate the needs assessments with the responses. Integration of the international responses with national response also must be improved.

Cooperative, strategic logistics planning should be attempted. Information sharing about logistic situations must be improved and prioritized (especially between the military and civilian actors). The lack of information was due to the lack of trained, local staff and appropriate connectivity.

\section{Coordination}

Life-saving equipment and supplies were delayed at ports of entry because of a failure to modify customs regulations to simplify the receipt of goods during catastrophic events. This includes the receipt of IT and communications equipment donated for the relief efforts.

Customs clearance procedures were developed by national authorities to import and use telecommunications equipment during the important first hours after a major destructive event without imposing customs duties. Licensing requirements should be waived, and certain immunities should be granted to foreign emergency telecommunications personnel.

Regarding logistics, competing coordination mechanisms created chaos. Communication and coordination between field-level operation centers and the national level were not always clear. 
Better ownership and involvement in logistics coordination by relief agencies are needed. Collaboration was done mostly on an ad hoc basis and only in response to clearly defined needs. A stronger commitment to "preemptive" coordination and advertisement of "assets available" lists is required. In some locations, better linking of national logistics coordination mechanisms with international mechanisms is needed.

\section{Filling gaps in provision of available services}

Better preparedness would enable a more effective response to future crises. Therefore, focused attention is needed on disaster preparedness and its advocacy. Information systems for tracking human resources and supplies chain monitoring, and such should be developed as part of preparedness. The required personnel should be trained on its usage, so that during a crisis, actual deployment of the system and its effective usage would avoid the need to learn how to use new systems and processes and procedures.

Overwhelming agency and bilateral assistance fostered a great deal of chaos and inadequate coordination. Better linkage of the logistics of the national responses to the international response would help. More standby capacity for temporary warehousing, more sharing of assets, and establishing common logistics services also would be useful.

\section{Capacity building}

It is imperative to build on the success of the Tsunami relief IT and communication programs currently in place. There is a need to consolidate, enhance, and deploy "best of breed" applications and technologies for global use in disaster preparedness, response, and recovery. Information technology and telecommunications functions should be viewed as strategic components of the disaster relief effort and $a$ foundation for building comprehensive resiliency and preparedness plans. Information technology and telecommunications support must be designated as "immediate deployment resources" in any crisis. Development and training of staff should support tracking systems and better tools to link different coordination centers.
Interagency coordination of logistics assistance needs to be strengthened. Establishing links between government mapping and assessment agencies and the international responses are needed, and vice versa.

\section{Recommendations}

Information technology and telecommunications should be a strategic partner in the development of national disaster management plans (including preparedness plans) and should be involved from Day 1 during the disaster response phase.

It is suggested that a governing process is needed to coordinate the sharing of IT and telecommunication skills and infrastructure between UN agencies and public and private enterprises. Also, it should be a first point of contact in the development of a coordinated IT disaster response.

Information technology-enabled operations rooms within each country office linked to national disaster management programs must be in place to ensure the readiness of countries. Local capacities in ministries must be strengthened in IT, telecommunications, and logistics.

An emergency management information system should be developed to manage communication, coordination, track resources, and staff. It must have the capacity to share information with all key players.

All Member States should ratify the Tampere Convention and ensure that related SOPs are implemented in national legislation to allow unhindered importation; and the use of emergency equipment and related human resources (i.e., no import duties and regulatory barriers and licensing) for relief efforts.

\section{Summary}

Strategic planning of logistical needs during a crisis should be maintained and shared. Contingency planning is needed to contain logistics components, for example, alternate customs regimes, logistics capacity assessments, strategic hubs identified (possibly regional), and supply stockpiling agreements. Better coordination and information sharing is required on the logistics situation, including understanding the needs and pipeline resources. 